\title{
The necrotising vasculitides
}

Necrotising vasculitis was first described 120 years ago by Kussmaul and Maier' in a young man with features of classic polyarteritis nodosa. Fifty years ago Wegen$\mathrm{er}^{2}$ and others ${ }^{3}$ recognised patients with clinical and pathological features that were distinct from those of polyarteritis nodosa, today's Wegener's granulomatosis. Twenty years later Churg and Strauss ${ }^{4}$ published a description of cases with asthma, eosinophilia, and necrotising vasculitis affecting predominantly medium sized vessels with necrotising granulomas. Thus a range of diseases with variable clinical and pathological features was recognised. Zeek $^{5}$ divided the vasculitides according to vessel size, and included a further category, an arteritis of small vessels often associated with hypersensitivity. More recent classifications use pathogenic as well as histological features, ${ }^{6-8}$ but all remain controversial because of differences of opinion and terminology, and incomplete knowledge about the pathogenesis. The recognition of overlap syndromes and cases that do not appear to fit well into any particular group add to the confusion. ${ }^{910}$

For the thoracic physician the small and medium sized vessel vasculitides form more of a clinical dilemma than those affecting large vessels; these include polyarteritis nodosa, the allergic granulomatous angiitis of Churg and Strauss, Wegener's granulomatosis, and possibly microscopic polyarteritis as a separate category. The features of each of these multisystem diseases have been described, but in some cases the series is based only on clinical identification of cases without histological proof of the diagnosis and this may lead to bias in the results, depending on the criteria used for selection. It is preferable to use data from series with biopsy proved diagnoses to establish these characteristics, even though it is recognised that often all the histological features may not be present simultaneously" and that reporting of the organs affected may be biased by the major interest of the referral centre collecting the cases. Data from series selected on this basis are shown in the table. ${ }^{412-17}$

The classical presentation of the Churg-Strauss syndrome is initially with asthma and frequently allergic rhinitis, and subsequently with evidence of vasculitis, at which time the asthma often abates. ${ }^{412}$

Address for reprint requests: Dr E H Sawicka, Brompton Hospital, London SW3 6HP.
The latter development is accompanied by fever, weight loss, and anaemia, with the laboratory findings of leucocytosis, an eosinophilia of up to $81 \%$ of the total white cell count and an absolute eosinophil count of more than $1.5 \times 10^{9} / 1$, and a raised erythrocyte sedimentation rate (ESR). The haematological findings are good indicators of disease activity. The chest radiograph has shown patchy pneumonic or nodular infiltrates in anything from $27 \%$ to $85 \%$ of cases. Cardiac abnormalities were a major feature of the original series, myocardial or pericardial disease occurring in $85 \%$ cases and causing heart failure in $38 \%$. Although disease affecting the cardiovascular system is not specified in the series of Chumbley et al, ${ }^{12}$ $33 \%$ of deaths were due to cardiac causes. Neurological disease is common, usually affecting the peripheral nervous system and causing a mononeuritis multiplex, and so is abdominal pain; but serious gastrointestinal problems are found in only one quarter of cases. Minor renal abnormalities occur, though progressive renal failure is rare. Biopsy of the kidneys may show a focal glomerulonephritis affecting only a few glomeruli, diffuse or focal interstitial nephritis with eosinophilic infiltrates, granulomas, and necrotising vasculitis.

Classical polyarteritis nodosa is a necrotising vasculitis affecting the medium sized muscular arteries, particularly at the bifurcation of vessels, leading to the formation of aneurysms that may rupture or thrombose to cause tissue infarction. ${ }^{1819}$ The aneurysms may be demonstrated by angiography or computed tomography of the renal, mesenteric, or hepatic vessels and they have been shown to resolve with treatment. ${ }^{20} 21$ Aneurysm formation has been reported in other forms of vasculitis, ${ }^{22}{ }^{23}$ but their distribution, location, and density help to distinguish them from those of classic polyarteritis nodosa. ${ }^{20}$ Hypertension is a common finding, particularly in relation to healed arteritis. The lung, except in the rare cases with pulmonary hypertension, and the spleen are characteristically spared by the disease. ${ }^{51724}$ The major renal abnormalities are areas of infarction and ischaemia with fibrinoid necrosis of the larger vessels. ${ }^{18}$

Davson et al ${ }^{24} 25$ recognised a subgroup of cases of polyarteritis nodosa affecting small vessels and characterised by a necrotising glomerulitis with crescent formation and interstitial nephritis, often without macroscopic aneurysm formation, and they suggested 
Clinical and pathological features of some of the necrotising vasculitides (figures are means derived from series)

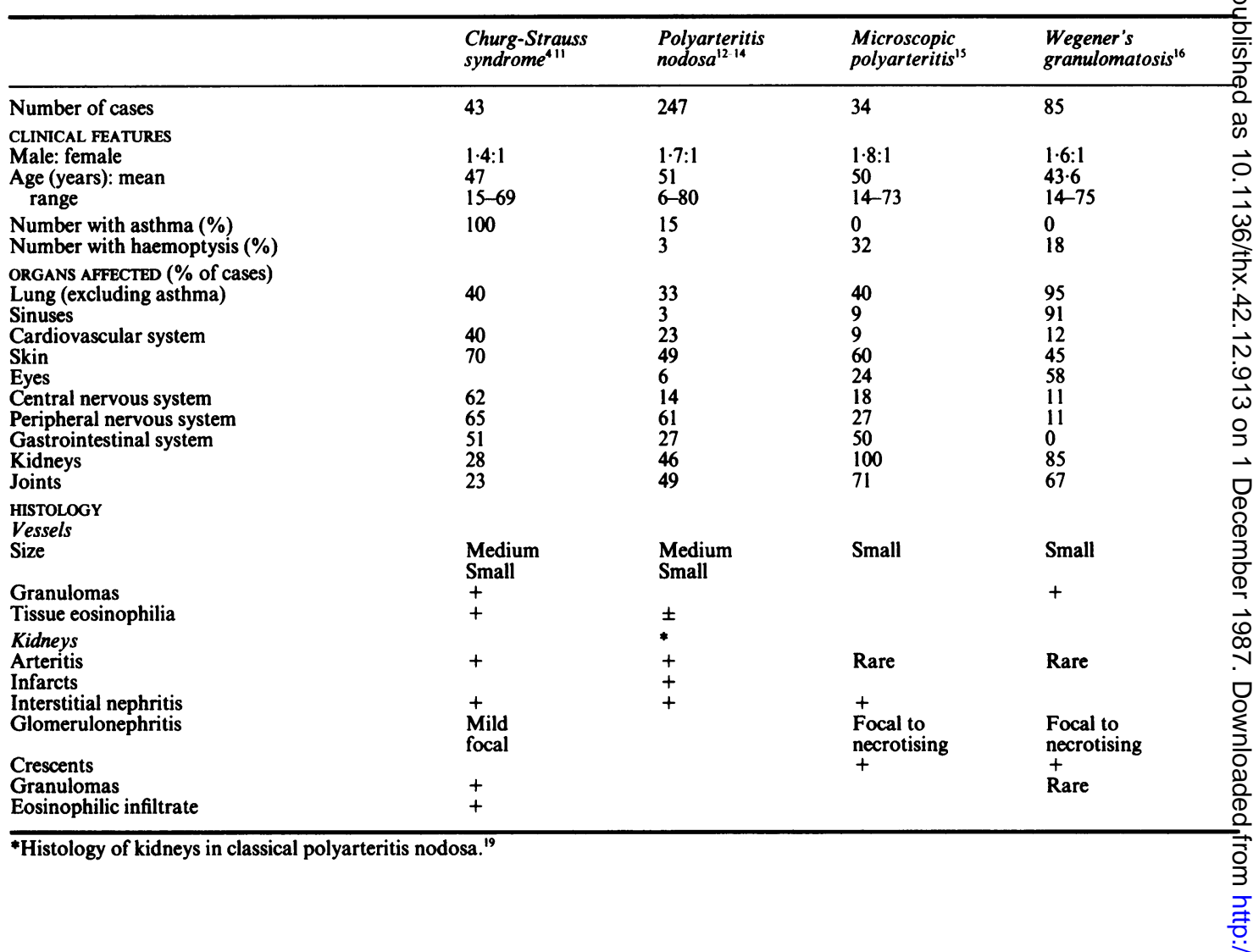

that this was a microscopic form of polyarteritis that differed from classical polyarteritis nodosa. This distinction has been maintained by Heptinstall, ${ }^{19}$ whereas Fauci et al include microscopic polyarteritis in the hypersensitivity vasculitides, accepting that polyarteritis nodosa affects both medium and small vessels and may be associated with glomerulonephritis. Examination of three recent major series of cases of polyarteritis nodosa suggests that the authors have also failed to distinguish between these groups. ${ }^{13-15}$ In these series patients presented with systemic symptoms of fever and weight loss in 36-70\% of cases, and more than $25 \%$ were hypertensive. The organs most commonly affected were the skin (with lesions ranging from purpura to ulcers), joints, and peripheral nervous system, the disease presenting as mononeuritis multiplex. Asthma was found in $8-22 \%$ of patients, in whom eosinophilia was often noted. Although pulmonary shadowing occurred in $13-38 \%$ of radiographs, haemoptysis was uncommon, in contrast to the findings in a series of patients with microscopic polyarteritis. Deaths from polyarteritis nodosa were related to severity of the gut or renal disease, the biopsy specimens in the latter cases showing a vas culitis and focal glomerulonephritis. ${ }^{15}$

The clinical features of patients with microscopie polyarteritis, diagnosed by renal biopsy, and clinica evidence of systemic vasculitis were reported recen tly. ${ }^{16}$ Those with recognisable syndromes or patho윽 logical evidence of other conditions associated with a small vessel vasculitis were excluded and angiography did not show aneurysms. These patients presented with constitutional symptoms $(76 \%)$, including fever. $(41 \%)$. Minor upper respiratory tract symptoms occurred in about one third but only $9 \%$ had sinusitis, Myalgia or arthralgia and cutaneous evidence of vasculitis was found in more than half. One third of patients had had haemoptysis, most of these hak radiographic and lung function evidence of intrapule monary haemorrhage, which was life threatening in four cases. Pleuritis and pleural effusion were less common. Abdominal symptoms and gastrointestinat haemorrhage occurred in one third of cases. Diseas $\Phi^{+}$ affecting the peripheral nervous and cardiovasculaf systems was unusual. All the patients had anaemia, $\mathbb{Z}$ raised ESR, microscopic haematuria, and a raise 

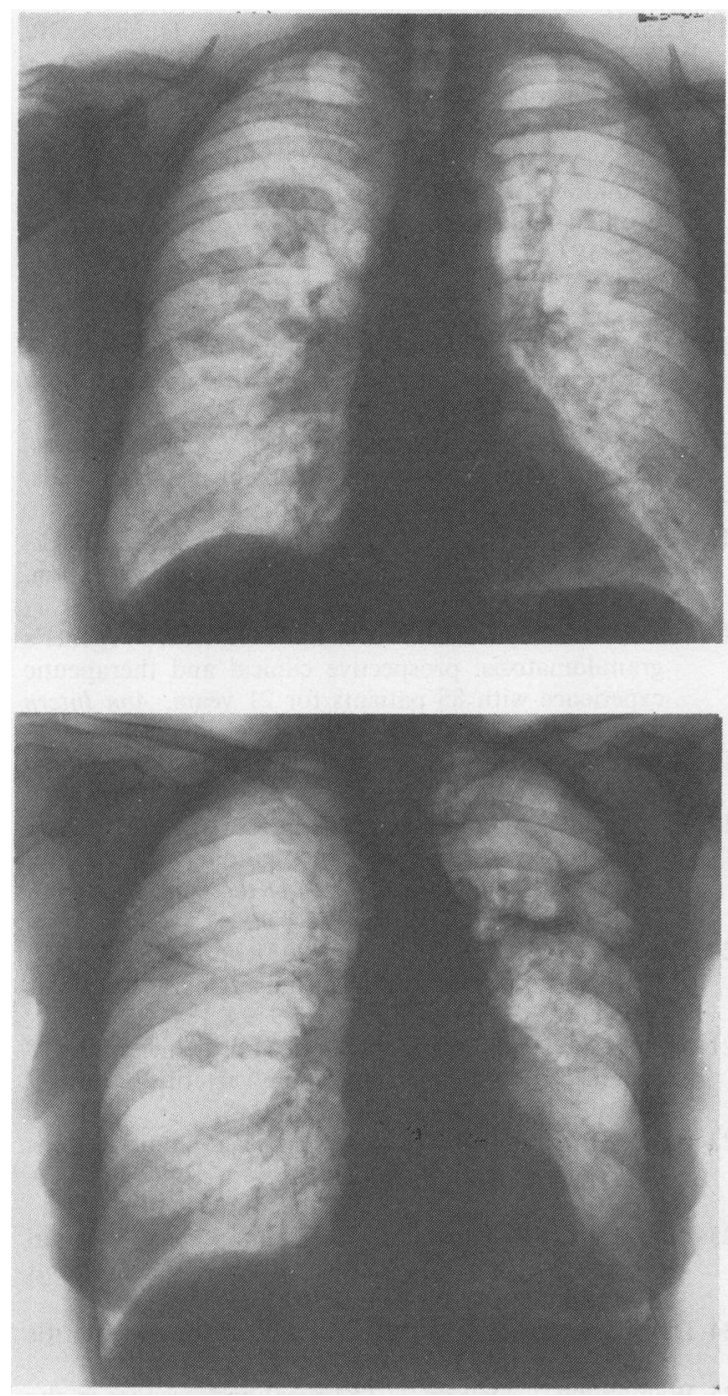

Chest radiographs of two patients with untreated, biopsy proved Wegener's granulomatosis. (Reproduced by courtesy of Dr I Kerr.)

plasma creatinine concentration, and all were negative for hepatitis B surface antigen. Many of these features suggest that this group is distinct from classical polyarteritis nodosa. There are, however, some similarities between this condition and that of Wegener's granulomatosis, with similar renal lesions and pulmonary haemorrhage reflecting small vessel disease occurring in both.

Wegener's granulomatosis remains an uncommon disease, with only four cases collected during eight years in one district general hospital. ${ }^{26}$ It is characterised by necrotising granulomatous lesions of the upper and lower respiratory tract, glomerulonephritis, and small vessel vasculitis. A limited form with minor renal disease has also been described. ${ }^{27}$ It frequently presents with sinusitis $(67 \%)$, nasal discharge $(22 \%)$ that may be blood stained, and pulmonary shadowing (71\%), often in the form of multiple cavitating nodules and asymptomatic in half the cases. ${ }^{17}$ Haemoptysis is the most common respiratory symptom ${ }^{17}$ and massive alveolar haemorrhage has been described. ${ }^{28}$ Middle ear disease secondary to sinusitis and eye disease with severe proptosis may occur. In contrast to polyarteritis nodosa, hypertension is uncommon at presentation despite evidence of renal disease and abnormalities seen on renal biopsy in over $70 \%$ of cases. The histological changes vary from mild focal and segmental glomerulonephritis with little impairment of function to a severe necrotising glomerulonephritis with crescent formation. Granulomas and arteritis are rarely seen in biopsy specimens. Anaemia, leucocytosis, and a raised erythrocyte sedimentation rate are usual at presentation, and mild eosinophilia has been observed. ${ }^{29}$

When a patient has clinical evidence of systemic vasculitis, it is important to establish a histological diagnosis if at all possible to confirm the diagnosis, give some idea of the likely clinical course and prognosis, and to determine the appropriate treatment. This is most likely to be achieved by obtaining biopsy specimens of affected tissue. In cases where other biopsies are inappropriate, a renal biopsy can often be performed safely, and though the histological appearance is usually non-specific, it may be helpful when taken in the clinical context and it can influence management ${ }^{30}$ Transbronchial biopsy has been reported to provide specimens with diagnostic histological features in Wegener's granulomatosis, and as early diagnosis and treatment are essential it is a possible alternative to open lung biopsy if this cannot be carried out. A serological test may be available for the diagnosis of Wegener's granulomatosis in the new future.In 1985 an IgG antibody against the cytoplasm of neutrophils was detected in the serum of patients with Wegener's granulomatosis but not with other forms of vasculitis. ${ }^{334} \mathrm{~A}$ similar antibody, but with different binding specificity, has also been detected in a small number of patients with microscopic polyarteritis. ${ }^{35}$ Whether these antibodies are important in the pathogenesis of these diseases and whether they will prove to be diagnostic remains to be seen, but they will probably provide a marker with which to follow disease activity.

If untreated the vasculitides are almost uniformly fatal, with a five year survival of less than $15 \% .^{513}$ 
The use of corticosteroids has increased this to $60 \%$ in patients with Churg-Strauss syndrome. ${ }^{12}$ Patients with polyarteritis nodosa also respond to treatment with corticosteroids; one study failed to show any further benefit from the routine addition of cytotoxic therapy. ${ }^{14}$ By contrast, the treatment of choice for Wegener's granulomatosis and microscopic polyarteritis is a combination of cyclophosphamide with high dose prednisolone for induction, which is reduced to an alternate day regimen for maintenance. This has produced remission of Wegener's granulomatosis in $93 \%$ of cases. Plasmapheresis is also used to manage severe pulmonary haemorrhage or rapidly progressive renal failure. ${ }^{162829}$ Recently DeRemee et $a \beta^{77}$ have reported the successful treatment of 11 of 12 patients with Wegener's granulomatosis with antibiotics, particularly co-trimoxazole. These findings lead the authors to speculate on whether Wegener's granulomatosis is triggered by infection in a susceptible host. This problem will surely be resolved by the time we celebrate Freidrich Wegener's 100th birthday.

EH SAWICKA

Brompton Hospital London SW3 6HP

\section{References}

1 Kussmaul A, Maier K. Uber eine bischer nicht beschreibe eigenthumliche Arteriener-krankung (Periarteritis nodosa), die mit Morbus Brightii und rapid fortschreitender allgemeiner Muskellahmung einhergeht. Deutsche Arch Klin Med 1866;1:484-517.

2 Wegener F. Periarteritis nodosa und ihre Bedeutung bei einem Fall von chronischen Ruhr. Deutsch Z Gerichtl Med 1935;25:93-101.

3 Klinger H. Glenzformer der Periarteritis nodosa. Frankfurt Z Pathol 1932;42:455-80.

4 Churg J, Strauss L. Allergic granulomatosis, allergic angiitis and periarteritis nodosa. Am $J$ Pathol 1951;27:277-301.

5 Zeek PM. Periarteritis nodosa and other forms of necrotizing angiitis. $N$ Engl J Med 1953;27:277-301.

6 Alarcon-Segovia D. The necrotizing vasculitides. A new pathogenic classification. Clin North Am 1977;61:24160.

7 Fauci AS, Haynes BF, Katz P. The spectrum of vasculitis: clinical, pathologic, immunologic and therapeutic considerations. Ann Intern Med 1978;89:660-76.

8 Cupps TR, Fauci AS. The vasculitic syndromes. $A d v$ Intern Med 1982;27:315-44.

9 Leavitt RY, Fauci AS. The polyangiitis overlap syndrome: classification and prospective clinical experience. Am J Med 1986:81:79-85.

10 Henochowicz S, Eggensprenger D, Pierce L, Barth WF.Necrotizing systemic vasculitis with features of both Wegener's granulomatosis and Churg Strauss vasculitis. Arth Rheum 1986;29:565-9.
11 Lanham JG, Elkom KB, Pusey CD, Hughes GR믐 Systemic vasculitis with asthma and eosinophilia: के clinical approach to the Churg-Strauss syndrome $\overline{\bar{c}}$ Medicine (Baltimore) 1984;63:65-81.

12 Chumbley LC, Harrison BG, DeRemee RA. Allergic granulomatosis and angiitis (Churg-Strauss synes drome): report and analysis of 30 cases. Mayo Clin:Proc 1977;52:477-84.

13 Frohnert PP, Sheps SG. Long-term follow-up study of periarteritis nodosa. Am J Med 1967;43:8-14.

14 Leib ES, Restive C, Pauliss HE. Immunosuppressive and corticosteroid therapy of polyarteritis nodosa. Am Med 1979;67:941-7.

15 Cohen RD, Conn DL, Ilstrup DM. Clinical features, $\vec{N}$ prognosis and response to treatment in polyarteritis.0 Mayo Clin Proc 1980;55:146-55.

16 Savage COS, Winearls CG, Evans DJ, Rees AJ, Lock-음 wood CM. Microscopic polyarteritis: presentation, pathology, prognosis. $Q J$ Med 1985;56:467-83.

17 Fauci AS, Haynes BF, Katz P, Wollf SM. Wegener's granulomatosis: prospective clinical and therapeutic experience with 85 patients for 21 years. Ann Intern? Med 1983;98:76-85.

18 Rose GA, Spencer H. Polyarteritis nodosa. $Q J$ Med $_{\vec{G}}$ 1957;26:43-81.

19 Heptinstall RH. Polyarteritis (periarteritis) nodosa, other. forms of vasculitis, and rheumatoid arthritis. In: Heptinstall RH, ed. Pathology of the kidney. Boston: Little Brown and Co,1983:793-838.

20 Travers RL, Allison DJ, Brettle RP, Hughes GRV. 꿀 Polyarteritis nodosa: a clinical and angiograph analysis $\frac{}{\Phi}$ of 17 cases. Semin Arth Rheum 1979;8:184-99.

21 Wilms G, Oyen R, Waer M, Baert AL, Michielsen P. CT $\overrightarrow{\overrightarrow{0}}$ demonstration of aneurysms in polyarteritis nodosa. $J \overline{3}$ Comput Assist Tomogr 1986;10:513-5.

22 Baker SB, Robinson DR. Unusual renal manifestations of Wegener's granulomatosis. Am J Med 1978;64:883 9.

23 Longstreth PL, Korobkin M, Kalubinskas PJ. Renal microaneurysms in a patient with systemic lupus ${ }_{\sigma}^{\times}$ erythematosus. Radiology 1974;113:65-6.

24 Davson J, Ball J, Platt $\mathbf{R}$. The kidney in periarteritis nodosa $Q J$ Med 1948;17:175-202.

25 Wainwright J, Davson J. The renal appearances in the

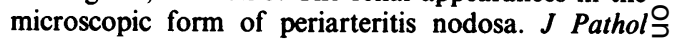
Bacteriol 1950;62:189-96.

26 Scott DGI, Bacon PA, Elliott PJ, Tribe CR, Wallington TB. Systemic vasculitis in a district general hospital 1972-1980: clinical and laboratory features. $Q J$ Med $\odot$ 1982;51:292-311.

27 Carrington CB, Liebow AA. Limited forms of angiitis and granulomatosis of Wegener's type. Am J Med
1966;41:497-527.

28 Howarth SJ, Savage COS, Carr D, Hughes JMB, Rees AJ. Pulmonary haemorrhage complicating $\mathbb{\Phi}$ Wegener's and microscopic polyarteritis. $\mathrm{Br}$ Med $\mathrm{J} \stackrel{\text { ? }}{-}$ 1985;290:1775-8.

29 Pinching AJ, Lockwood CM, Pussell BA, et al. Wegener's granulomatosis observations on 18 patients with severe renal disease. $Q J$ Med 1983;52:435-60.

30 Mills JA, McCroskery PA. Periarteritis nodosa, hypersensitivity angiitis and related syndromes: clinical $\sigma$ and pathological aspects. In: Bacon PA, Handler NM, $ᄋ$ 
eds. The kidney and rheumatic disease. London: Butterworths Scientific, 1982:159-62.

31 Givens CD, Newman JH, McCurley TL. Diagnosis of Wegener's granulomatosis by transbronchial biopsy. Chest 1985;88:794-6.

32 Ackerman Z, Orbach H, Burstein M, Breuer R. Transbronchial biopsies in Wegener's granulomatosis. Ann Intern Med 1986;105:801-2.

33 Van der Woude FJ, Rasmussen N, Lobatto S, et al. Autoantibodies against neutrophils and monocytes: tool for diagnosis and marker of disease activity in Wegener's granulomatosis. Lancet 1985;i:425-9.

34 Gross WL, Ludemann G, Kiefer G, Lehmann H.
Anticytoplasmic antibodies in Wegener's granulomatosis. Lancet 1986;i:806.

35 Lockwood CM, Bakes D, Jones S, Whitaker KB, Moss DW, Savage COS. Association of alkaline phosphatase with an autoantigen recognised by circulating anti-neutrophil antibodies in systemic vasculitis. Lancet 1987;i:716-9.

36 Fauci AS, Katz P, Haynes BF, Wolff SM. Cyclophosphamide therapy of severe systemic necrotising vasculitis. $N$ Engl J Med 1979;301:235-8.

37 DeRemee RA, McDonald TJ, Weiland LH. Wegener's granulomatosis: observations on treatment with antimicrobial agents. Mayo Clin Proc 1985;60:27-32. 